Research Article

\title{
Effect of Dry-Wet Cycling on the Mechanical Properties of High-Water Materials
}

\author{
X. L. Zhou $\mathbb{D}^{1},{ }^{1}$ C. W. Liu $\left(\mathbb{D},{ }^{1}\right.$ Y. Liu, ${ }^{2}$ C. Wang, ${ }^{3}$ and Y. J. Ma ${ }^{1}$ \\ ${ }^{1}$ College of Water Resource and Hydropower, Sichuan University, Chengdu 610065, China \\ ${ }^{2}$ School of Civil Engineering, Anhui Jianzhu University, Hefei 230601, China \\ ${ }^{3}$ School of Engineering, University College Cork, Cork T13 YT20, Ireland \\ Correspondence should be addressed to C. W. Liu; liuchangwu@scu.edu.cn
}

Received 6 August 2019; Revised 17 January 2020; Accepted 10 February 2020; Published 10 March 2020

Academic Editor: Constantin Chalioris

Copyright ( $\odot 2020$ X. L. Zhou et al. This is an open access article distributed under the Creative Commons Attribution License, which permits unrestricted use, distribution, and reproduction in any medium, provided the original work is properly cited.

\begin{abstract}
As a new grouting reinforcement material, high-water materials (HWMs) are being increasingly applied in different fields. This means that the environment in which these HWMs are employed are varied and increasingly complex. The dehydrating and saturation cycle of HWM caused by changes in the environment is referred to as the dry-wet cycle. To explore the influence of the dry-wet cycle on the mechanical properties of HWMs, uniaxial compression tests were performed on specimens with different water-to-cement ratios under different dry-wet cycles. The degradation rate of the peak stress and elastic modulus increased with an increase in the water-to-cement ratio. The failure mode of specimens changed from splitting failure to shear-splitting failure during the dry-wet cycle. The results of scanning electron microscope and X-ray diffraction showed that an HWM with a low water-to-cement ratio is relatively dense; therefore, the carbonization process is slow during dehydration. Raw materials were present after hydration and hardening reaction. Thus, the strength recovery ability is strong in materials with a low water-tocement ratio during the saturation process. Finally, the experimental results can provide guidance for selecting materials with different water-to-cement ratios and control measures for dry-wet cycle can be determined according to different engineering environments.
\end{abstract}

\section{Introduction}

China has abundant coal reserves; however, many of these reserves are located underwater, buildings, and railways. With advancements in coal mining technology, the traditional mining method is gradually being replaced by filling mining $[1,2]$. Gupta [3] reviewed the application of coal mine overburden $(\mathrm{OB})$ dump material for backfilling in underground mine voids created due to coal mining in deep seams/horizons. Gibert [4] assessed the potential of municipal compost as a carbon source. Initial filling materials include gangue, concrete, and solid paste [5]. However, these materials have many shortcomings such as a complicated filling process, high investment cost, and poor effect of filling goaf. Until the 1980s, high-water materials (HWMs) were widely used in mine filling, which resolved the problems associated with traditional filling materials [6-8]. For example, Chen's research [9] showed that backfill satisfies the strength requirements and effectively controls the surface subsidence.

Further improvements in production technology expanded the application of HWMs to gas drainage sealing, water shutoff, marine engineering, and soft soil foundation reinforcement $[10,11]$. In addition to having the properties required of grouting materials, an HWM exhibits good fluidity, rapid setting, early strength, controllable setting time, and good impermeability that cement slurry lacks. The use of HWM is gradually changing from being filling materials to being grouting materials. The application environment of HWMs is thus being gradually transferred from underground to surface.

However, when exposed to air, HWM tends to react with carbon dioxide, resulting in reduced strength and increased porosity [12]. Therefore, the durability of HWMs depends highly on environmental conditions. The increasing applications of HWMs in different fields means that the 
engineering environment in which these materials are employed are varied and increasingly complex. Alternating cycles of dehydration and saturation are commonly observed in HWM owing to a change in the level of underground water, river water, and water content of surrounding rocks. Furthermore, studies have found that HWMs dehydrate under pressure and saturate once the pressure is released [13]. The alternating dehydrating and saturation cycle of HWMs, caused by changes in the engineering environment, is referred to as the dry-wet cycle. The influence of the dry-wet cycle on rocks has been studied in depth; however, its influence on HWM has rarely been investigated [14-16]. For example, Shim [17] studied the self-healing properties of superabsorbent polymer (SAPs) gelling materials in eight wet/dry cycles. Some researchers have studied the mechanical properties and stability of rocks under the action of wet/dry cycles [18-20].

In the past [13], the environment wherein HWMs is used as filling material was relatively stable; thus, research on HWM has mainly focused on topics such as hydration hardening mechanism, physical and mechanical properties, and long-term creep characteristics [21, 22]. More environmental factors should be considered for evaluating the stability of HWM as grouting materials. For example, the effect of dry-wet cycles caused by environmental change on the durability of HWM is very significant. However, there are few studies on the dry-wet cycle of HWMs. The durability of HWM as grouting materials depends highly on environmental conditions. Therefore, it is of great significance to study the mechanical properties of HWM with different water-cement ratios under the dry-wet cycle. The research results can guide the selection of practical engineering materials.

\section{Materials and Methods}

2.1. Preparation of Samples. An HWM is composed of two main materials, one of which contains $\mathrm{A}$ and $\mathrm{A}-\mathrm{A}$ and the other contains $\mathrm{B}$ and $\mathrm{B}-\mathrm{B}$. The main composition of the four raw materials is listed in Table 1.

Currently, the water-to-cement ratio of HWMs commonly used in lab tests and field application varies between $2: 1$ and $7: 1$. A water-to-cement ratio of $2: 1$ implies that the weight of water is twice the sum of the weights of the four raw materials. To study the influence of the dry-wet cycle on the mechanical properties of HWMs, materials with waterto-cement ratios of $3: 1,4: 1$, and $5: 1$ were used in experiments. The ratio of the four raw materials $A: A-A: B: B-B$ is $1: 0.1: 1: 0.04$.

A thermometer was used to control the temperature of the test water at $20 \pm 2^{\circ} \mathrm{C}$. A measuring bucket was used to measure the amount of water. First, materials A and A-A were mixed in water for $5 \mathrm{~min}$. The same procedure was followed for materials B and B-B. Then, the two groups of liquid were poured together. When the mixture was about to solidify, it is injected into a mold with dimensions of $\Phi 50 \mathrm{~mm} \times 100 \mathrm{~mm}$. To improve the accuracy of the uniaxial compression test, the top of the specimens should be flat. Figure 1 shows the molding and processing of the specimens.
TABLE 1: Constitution and mass fraction of HWM.

\begin{tabular}{lc}
\hline Constitution & Semiquantitative (mass fraction) \\
\hline A & $\mathrm{CaO} \cdot 3 \mathrm{Al}_{2} \mathrm{O}_{3} \cdot \mathrm{CaSO}_{4}(76) 2 \mathrm{CaO} \cdot \mathrm{SiO}_{2}(24)$ \\
A-A & $\mathrm{Na}_{2} \mathrm{CO}_{3}(6) \mathrm{SiO}_{2}(69) \mathrm{BaBiO}_{3}(25)$ \\
B & $\mathrm{CaSO}_{4}(61) \mathrm{CaCO}_{3}(12) \mathrm{CaSO}_{4} \cdot 2 \mathrm{H}_{2} \mathrm{O}(27)$ \\
B-B & $\mathrm{SiO}_{2}(70) \mathrm{CaSO}_{4}(30)$ \\
\hline
\end{tabular}

The specimens obtained were kept in water for 7 days, as shown in Figure 2. The hydration and hardening process of specimens basically ended after this period. All the specimens were in the saturated state before dry-wet cycling tests were performed on them. To study the mechanical properties of HWMs during the dry-wet cycle, the saturated and dehydrated specimens were designed for each water-tocement ratio. The saturated and dehydrated states were denoted by the letters $\mathrm{B}$ and $\mathrm{S}$, respectively.

2.2. Test Methods. After curing for 7 days, the specimens were taken out and placed indoor at a temperature of $25 \pm 2^{\circ} \mathrm{C}$ for $24 \mathrm{~h}$, which was recorded as a dehydrating process. Then, the specimens were placed in water at a temperature of $20 \pm 2^{\circ} \mathrm{C}$ for another $24 \mathrm{~h}$, which was recorded as a saturation process. Dehydration for $24 \mathrm{~h}$ and saturation for $24 \mathrm{~h}$ were recorded as a dry-wet cycle.

For example, for a water-to-cement ratio of $3: 1$, there were twelve groups of specimens, and each group had three specimens. The first to sixth groups were used to study the saturated state, with the number of dry-wet cycles being $n=0,3,6,9,12$, and 15 , and numbered 3-B-0, 3-B-3, 3-B-6, 3-B-9, 3-B-12, and 3-B-15, respectively. The number 3-B-0 refers to a specimen in a saturated state after curing for 7 days. The remaining groups were used to study the dehydrating state, with the number of dry-wet cycles being $n=1$, $3,6,9,12$, and 15 , and numbered 3-S-1, 3-S-3, 3-S-6, 3-S-9, $3-\mathrm{S}-12$, and 3-S-15, respectively. The number 3-S-1 represents a specimen in the dehydrating state after $24 \mathrm{~h}$ of curing. For the same number of dry-wet cycles, the test time of the saturated specimens is $24 \mathrm{~h}$ longer than that of the dehydrated specimens, that is, the dry-wet cycle test time of 3-S-1 and $3-\mathrm{B}-1$ is $24 \mathrm{~h}$ and $48 \mathrm{~h}$, respectively. The marking and classification of samples are summarized in Table 2.

A uniaxial compression test was performed on the specimens by using the ETM mechanical experimental system. The loading method was controlled by displacement, and the loading speed was $3 \mathrm{~mm} \cdot \mathrm{min}^{-1}$. The microstructure and composition of the specimens with different dry-wet cycles were analyzed by SEM and XRD.

\section{Results}

The stress-strain curve is an important index to reflect the deformation and failure process of HWM. The typical stressstrain curve of the HWMs was analyzed using the stressstrain curve of 3-B-0. As shown in Figure 3, the deformation and failure process of the specimens can be divided into the following four processes. 

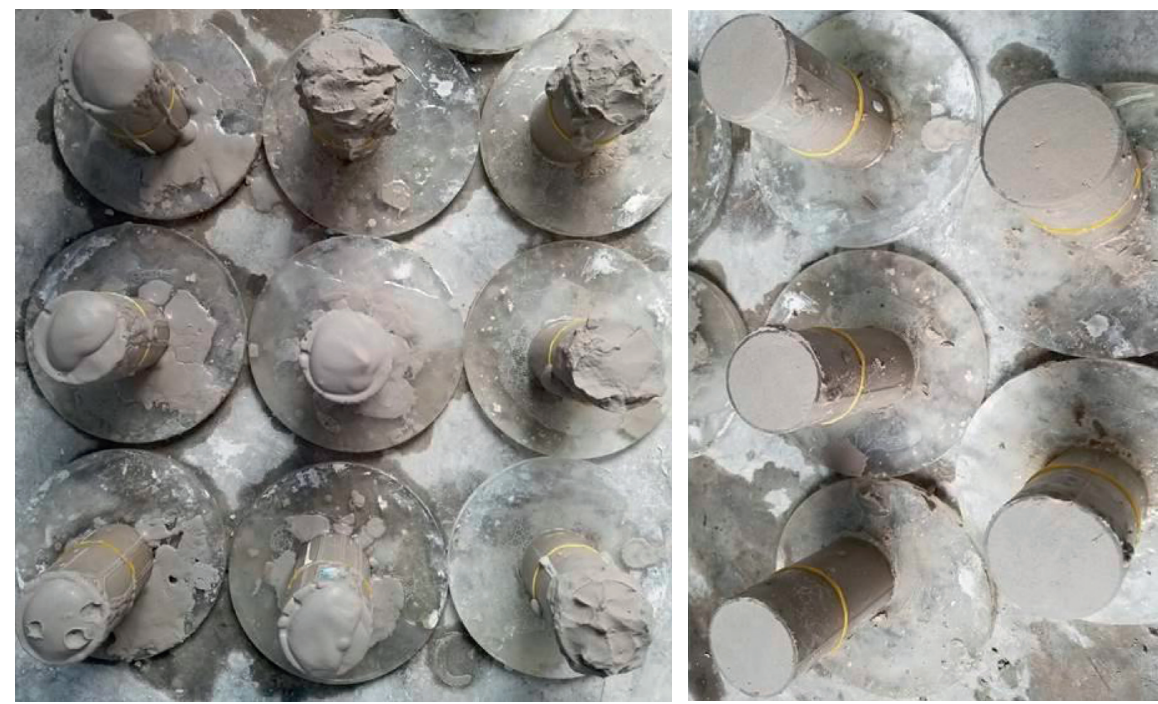

FIGURE 1: Specimen preparation.

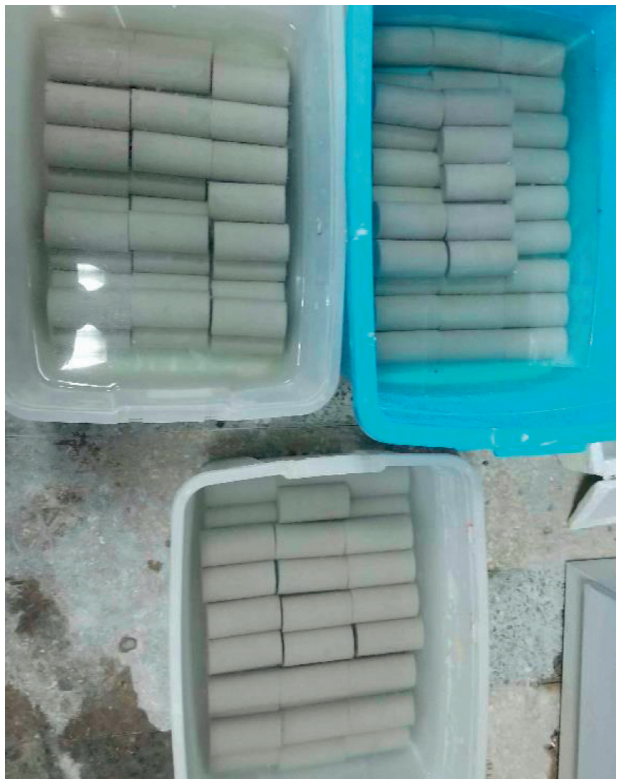

FIgURE 2: Specimen curing.

TABle 2: Number and classification of specimens.

\begin{tabular}{lcccccc}
\hline Cycles & \multicolumn{3}{c}{ Saturated } & \multicolumn{3}{c}{ Dehydrating } \\
& $3: 1$ & $4: 1$ & $5: 1$ & $3: 1$ & $4: 1$ & $5: 1$ \\
\hline 0 & 3 & 3 & 3 & - & - & - \\
1 & - & - & - & 3 & 3 & 3 \\
3 & 3 & 3 & 3 & 3 & 3 & 3 \\
6 & 3 & 3 & 3 & 3 & 3 & 3 \\
9 & 3 & 3 & 3 & 3 & 3 & 3 \\
12 & 3 & 3 & 3 & 3 & 3 & 3 \\
15 & 3 & 3 & 3 & 3 & 3 & 3 \\
\hline
\end{tabular}

$\mathrm{OA}$ is the first stage and is referred to as the pore compaction stage. The pores in the specimen were compacted, and there was no change in appearance at this stage. The second stage, represented by $\mathrm{AB}$, was the elastic stage.
The main feature of this stage is the appearance of water droplets on the surface. The next stage is $\mathrm{BC}$, or the yield stage, where the water inside the specimens was removed in large quantities. Cracks began to appear on the surface of the specimen at this stage. Cracks on the surface of the specimen grew rapidly in the last stage, i.e., the failure stage $\mathrm{CD}$. The stress-strain curve decreased gradually until the residual strength was reached. As an elastoplastic body, HWMs have high residual strength.

The most representative stress-strain curve of each group of three specimens was selected to study the basic mechanical characteristics. The stress-strain curves of specimens with different water-to-cement ratios under different dry-wet cycles are shown in Figure 4. As can be seen from Figure 4 , the shape of each curve is roughly the same, that is, it consists of the four stages mentioned above. The shape of the curves in Figure 4 shows that the materials were still elastic-plastic after the dry-wet cycles. However, the samples show different peak stresses, residual strengths, and peak strains under different dry-wet cycles. When the water-cement ratio was $3: 1$, the peak stress and residual strength of the samples increased with an increasing number of dry-wet cycles. When the water-cement ratio was $4: 1$, the peak stress and residual strength of the samples increased first and then decreased with an increasing number of dry-wet cycles. When the water-cement ratio was $5: 1$, the peak stress and residual strength of the samples decreased with an increasing number of dry-wet cycles. As shown in Figure 4, with the increase of water-cement ratio, the rate of declining stress after its peak decreased gradually. Therefore, the water-cement ratio is directly proportional to the plasticity of the materials.

3.1. Peak Stress Analysis. The peak stress of an HWM can be represented by its uniaxial compressive stress $\sigma_{c}$. It shows the stress value corresponding to the highest point of the stress-strain curve, as shown in Figure 3. The peak stress is calculated as follows: 


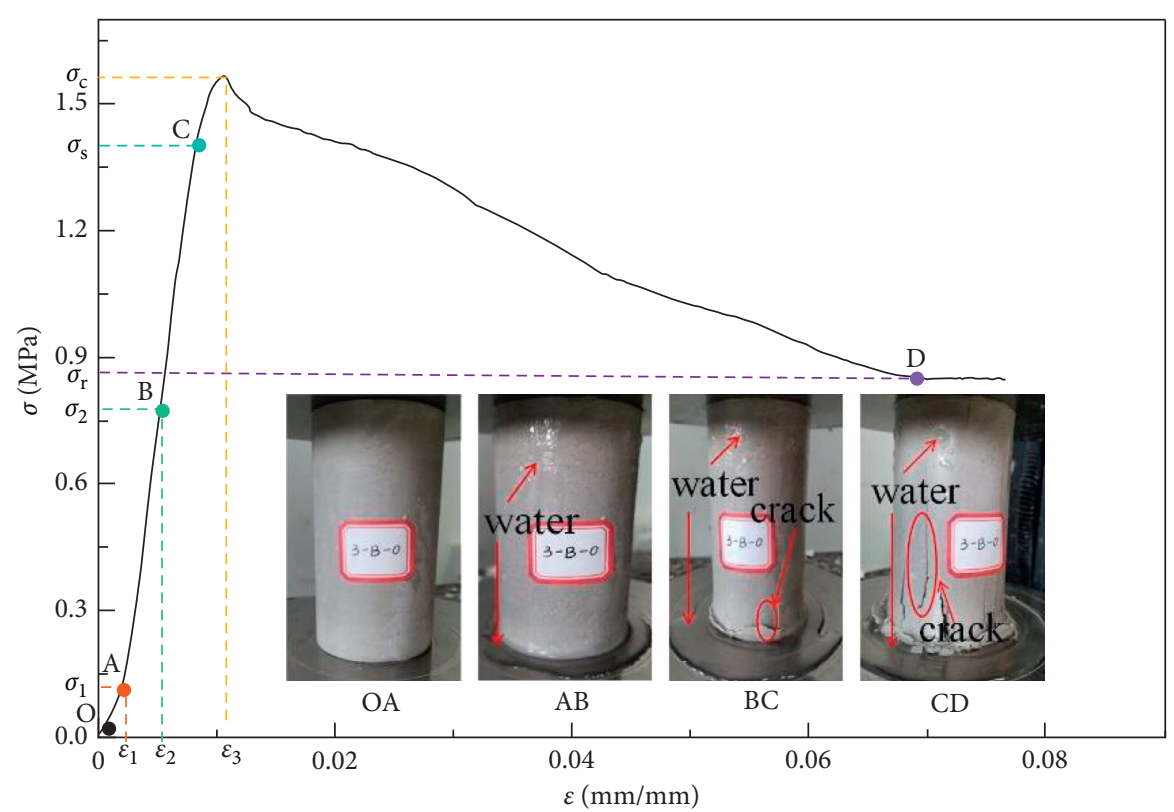

Figure 3: Typical stress-strain curves of the HWM.

$$
\sigma_{c}=\frac{P}{A}
$$

where $\sigma_{\mathrm{c}}$ is the peak stress, $P$ is the maximum load applied to compress the specimen, and $A$ is the compression area of the specimen, which is $1963.5 \mathrm{~mm}^{2}$. Table 3 lists the peak stress of specimens with different water-to-cement ratios under different dry-wet cycles. The peak stress listed in Table 3 is the average value of 3 specimens in each group.

At a water-to-cement ratio of $3: 1$, the peak stress in the saturated state is $1.58,1.65,1.73,1.78,1.80$, and $1.78 \mathrm{MPa}$ when the number of dry-wet cycles is $0,3,6,9,12$, and 15 , respectively. At the same water-to-cement ratio, the peak stress in the dehydrated state is $1.48,1.56,1.68,1.72,1.75$, and 1.73 MPa when the number of dry-wet cycles of 1, 3, 6, 9, 12 , and 15 , respectively. The peak stress in both the states first increased and then decreased with an increase in the number of dry-wet cycles. The peak stress is maximum when the number of dry-wet cycles is 12 . In the saturated state, as the number of dry-wet cycles increased from 0 to 15 , the peak stress of the specimens increased by $4.4 \%(n=3), 9.5 \%$ $(n=6), 12.7 \%(n=9), 13.9 \%(n=12)$, and $12.7 \%(n=15)$. In the dehydrated state, as the number of dry-wet cycles increased from 1 to 15 , the peak strength of the specimens increased by $5.4 \%(n=3), 13.5 \%(n=6), 16.2 \%(n=9), 18.2 \%$ $(n=12)$, and $16.9 \%(n=15)$. For the same number of drywet cycles, the peak stress of specimens in the dehydrated state is lower than that in the saturated state. HWMs recover strength by absorbing water and lose strength by losing water.

The tendency of the peak stress changing with an increase in the number of dry-wet cycles for specimens with a water-to-cement ratio of $4: 1$ is similar to that of specimens with a water-to-cement ratio of $3: 1$. The peak stress is the maximum when the number of dry-wet cycles is 6 . Similar to the trend observed for a water-to-cement ratio of $3: 1$, the peak stress in the dehydrated state is lower than that in the saturated state under the same number of dry-wet cycle.

Unlike the trend observed at water-to-cement ratios of $3: 1$ and $4: 1$, the peak stress decreased with an increase in the number of dry-wet cycles when the water-to-cement ratio is $5: 1$. In the saturated state, as the number of dry-wet cycles increased from 0 to 15 , the peak strength of the specimens decreased by $10.5 \%(n=3), 19.3 \%(n=6), 26.3 \%(n=9)$, $36.8 \%(n=12)$, and $43.9 \%(n=15)$. In the dehydrated state, as the number of dry-wet cycles increased from 1 to 15 , the peak stress of the specimens decreased by $7.8 \%(n=3), 17.6 \%$ $(n=6), 25.5 \%(n=9), 31.4 \%(n=12)$, and $39.2 \%(n=15)$.

It can be seen from the above results that, with an increase in the water-to-cement ratio, the adverse effect of drywet cycle on the HWM was more obvious. To intuitively understand the impact of the dry-wet cycle on the strength of HWMs, the relationship between the peak stress and dry-wet cycles was fitted by a curve (Figure 5).

When the water-to-cement ratio was $3: 1$, quadratic polynomial was adopted for curve fitting. The fitting curve equations are given as follows:

$$
\begin{aligned}
& \sigma_{c}(\text { saturated })=1.57179+0.03482 n-0.00137 n^{2}, \quad R^{2}=0.98302, \\
& \sigma_{c}(\text { dehydrating })=1.42678+0.05353 n-0.00222 n^{2}, \quad R^{2}=0.9922 \text {. }
\end{aligned}
$$

When the water-to-cement ratio was $4: 1$, cubic polynomial was adopted for curve fitting. The fitting curve equations are given as follows:

$$
\begin{aligned}
\sigma_{c}(\text { saturated })= & 0.88722+0.0359 n-0.00438 n^{2} \\
& +0.000127 n^{3}, \quad R^{2}=0.94678, \\
\sigma_{c}(\text { dehydrating })= & 0.7774+0.05466 n-0.00714 n^{2} \\
& +0.000216 n^{3}, \quad R^{2}=0.94553 .
\end{aligned}
$$




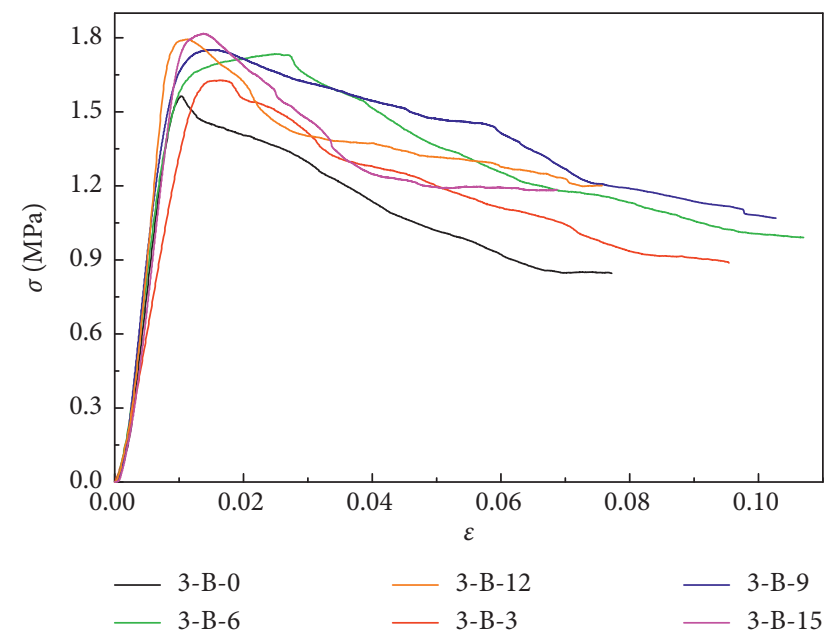

(a)
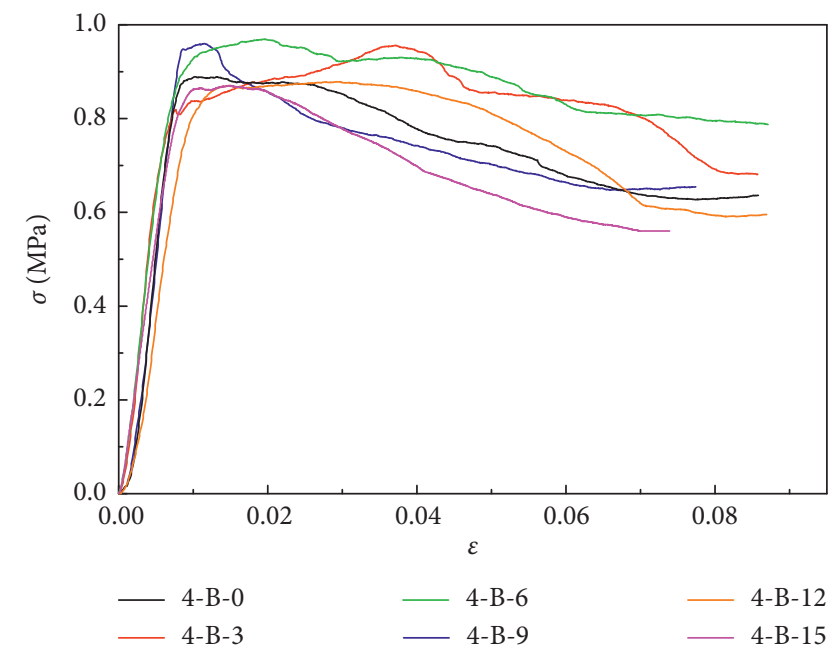

(c)

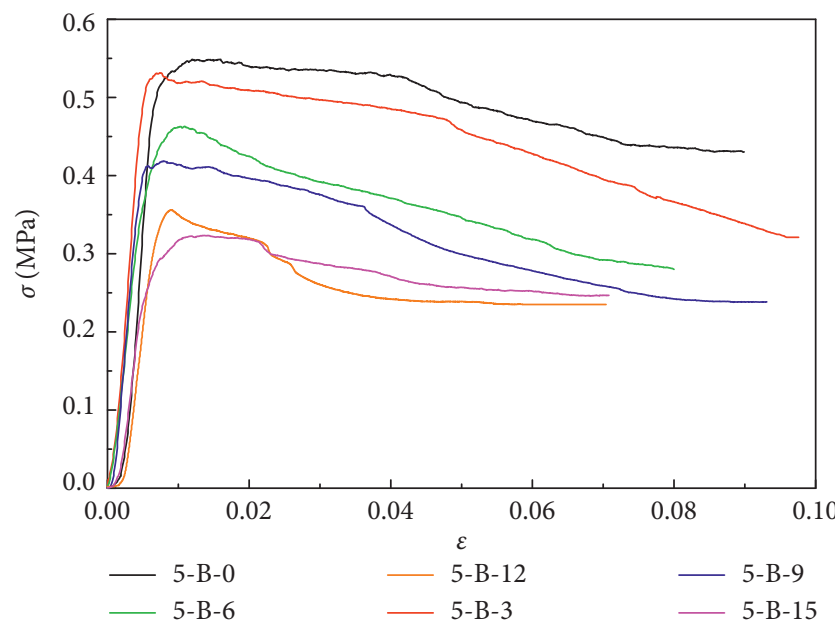

(e)

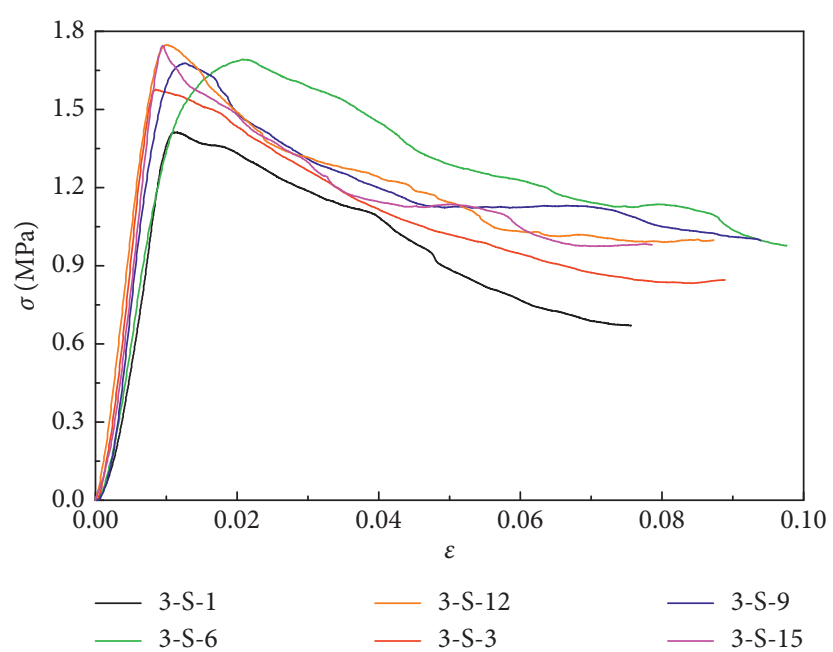

(b)
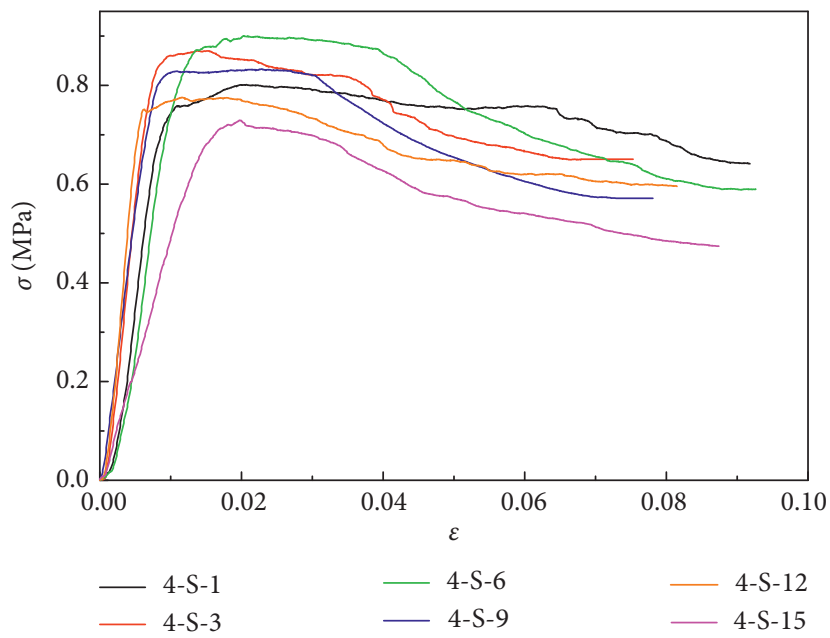

(d)

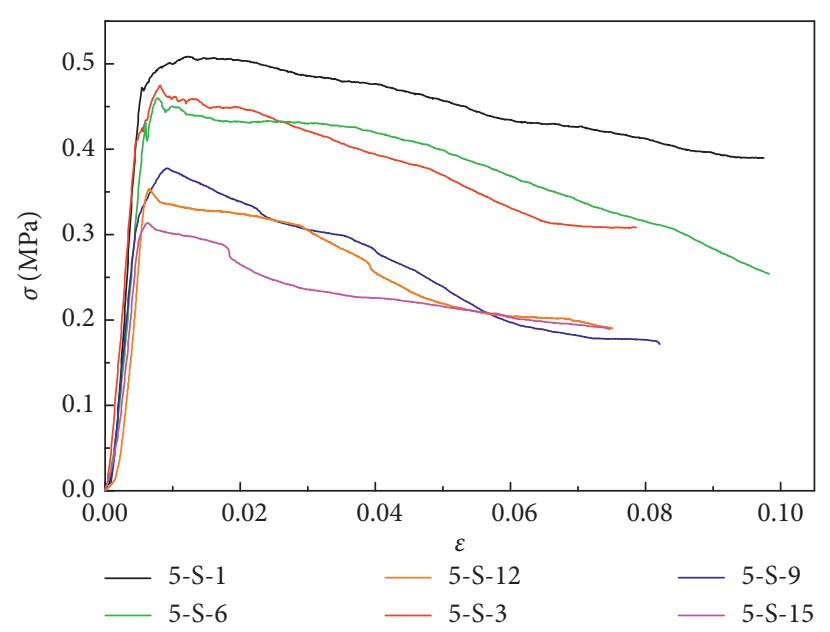

(f)

Figure 4: Stress-strain curves of specimens under different dry-wet cycles: (a) $3: 1$ saturated; (b) $3: 1$ dehydrated; (c) $4: 1$ saturated; (d) $4: 1$ dehydrated; (e) 5:1 saturated; (f) 5:1 dehydrated. 
TABLE 3: Average peak stress and elastic modulus of specimens under different dry-wet cycles.

\begin{tabular}{|c|c|c|c|c|c|c|c|}
\hline \multirow{2}{*}{ State } & \multirow{2}{*}{ Cycles } & \multicolumn{3}{|c|}{ Peak stress $(\mathrm{MPa})$} & \multicolumn{3}{|c|}{ Elastic modulus (MPa) } \\
\hline & & $3: 1$ & $4: 1$ & $5: 1$ & $3: 1$ & $4: 1$ & $5: 1$ \\
\hline \multirow{6}{*}{ Saturated } & 0 & 1.58 & 0.89 & 0.57 & 174 & 95 & 76 \\
\hline & 3 & 1.65 & 0.95 & 0.51 & 180 & 106 & 63 \\
\hline & 6 & 1.73 & 0.98 & 0.46 & 196 & 121 & 54 \\
\hline & 9 & 1.78 & 0.95 & 0.42 & 210 & 109 & 49 \\
\hline & 12 & 1.80 & 0.9 & 0.36 & 239 & 106 & 44 \\
\hline & 15 & 1.78 & 0.87 & 0.32 & 200 & 90 & 40 \\
\hline \multirow{6}{*}{ Dehydrating } & 1 & 1.48 & 0.83 & 0.51 & 148 & 90 & 65 \\
\hline & 3 & 1.56 & 0.87 & 0.47 & 175 & 92 & 60 \\
\hline & 6 & 1.68 & 0.91 & 0.42 & 187 & 110 & 52 \\
\hline & 9 & 1.72 & 0.84 & 0.38 & 197 & 91 & 48 \\
\hline & 12 & 1.75 & 0.78 & 0.35 & 218 & 88 & 42 \\
\hline & 15 & 1.73 & 0.72 & 0.31 & 182 & 85 & 34 \\
\hline
\end{tabular}

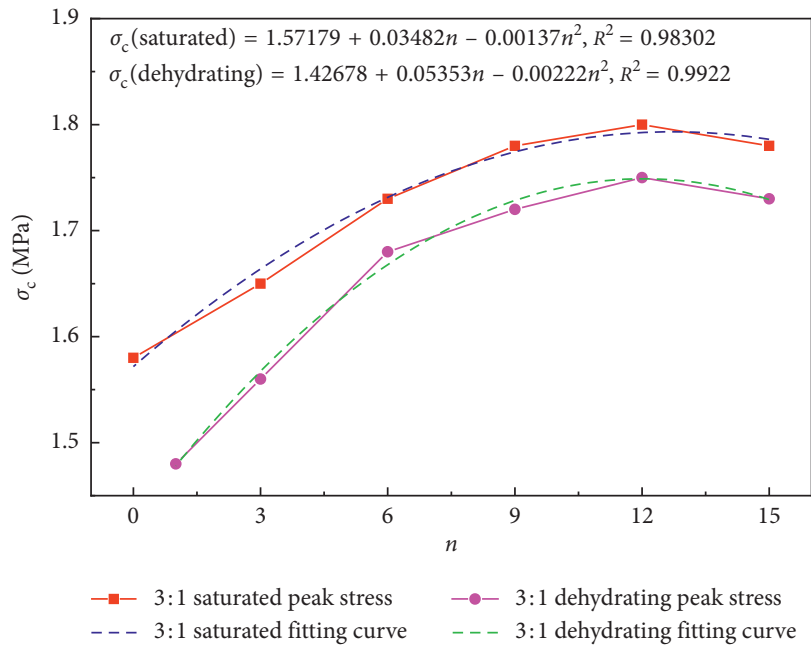

(a)

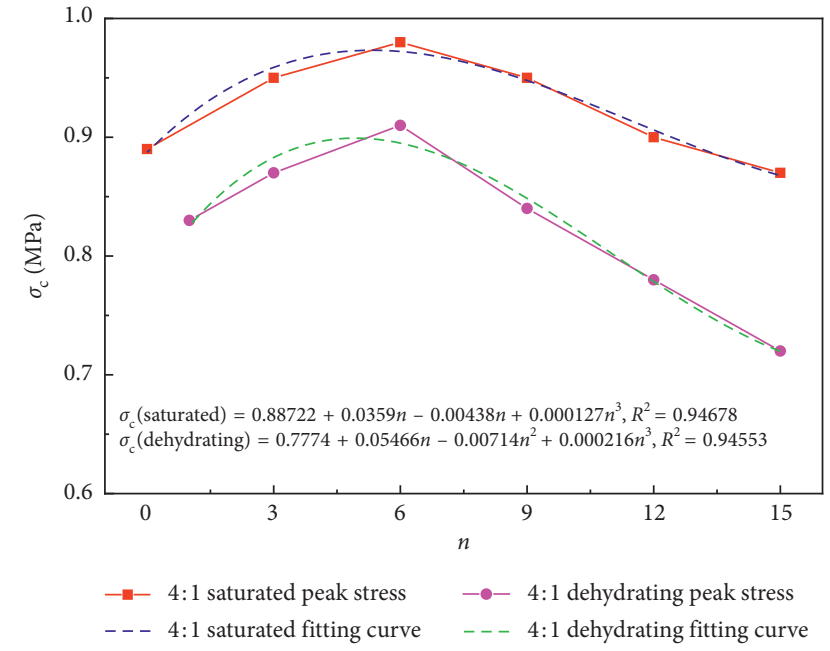

(b)

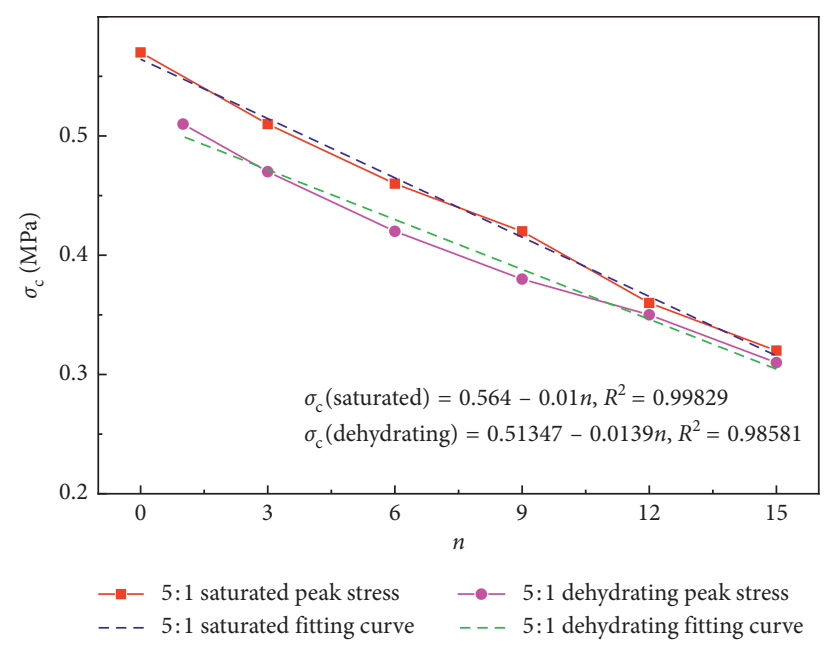

(c)

FIGURE 5: Relationship between peak stress and dry-wet cycles: (a) $3: 1$, (b) $4: 1$, and (c) $5: 1$. 
When the water-to-cement ratio was $5: 1$, linear fitting was adopted for curve fitting. The fitting curve equations are given as follows:

$$
\begin{aligned}
\sigma_{c}(\text { saturated })=0.564-0.01 n, & R^{2}=0.99829, \\
\sigma_{c}(\text { dehydrating })=0.51347-0.0139 n, & R^{2}=0.98581 .
\end{aligned}
$$

3.2. Elastic Modulus Analysis. Elastic modulus is an important indicator of a material's engineering properties. From a macroscopic point of view, elastic modulus is a measure of an object's resistance to elastic deformation. However, from a microscopic view, elastic modulus represents the bond strength between molecules. In this paper, the tangent modulus of the elastic segment of the stressstrain curve is defined as the elastic modulus. The elastic modulus is calculated by the following equation:

$$
E=\frac{\left(\sigma_{2}-\sigma_{1}\right)}{\left(\varepsilon_{2}-\varepsilon_{1}\right)},
$$

where $E$ is the elastic modulus, $\sigma_{1}$ and $\sigma_{2}$ are the stress values corresponding to the starting point $\mathrm{A}$ and end point $\mathrm{B}$ of the elastic stage, respectively, and $\varepsilon_{1}$ and $\varepsilon_{2}$ are the strain values corresponding to the starting point $\mathrm{A}$ and end point $\mathrm{B}$ of the elastic stage, respectively. The relationship between the elastic modulus and dry-wet cycles is shown in Figure 6.

The elastic modulus of the specimens at the three waterto-cement ratios changed in the same trend as the peak stress with an increase in the number of dry-wet cycles. When the water-to-cement ratio was $3: 1$, the elastic modulus for the two states increased initially before reaching a peak at 12 dry-wet cycles. After that, it experienced a moderate decrease. The tendency of the elastic modulus changing with an increase in the number of dry-wet cycles for specimens with a water-to-cement ratio of $4: 1$ is similar to that of specimens with a water-to-cement ratio of $3: 1$ ratio. When the number of dry-wet cycles was 6 , the elastic modulus was the maximum. However, when the water-cement ratio was $5: 1$, the elastic modulus of the two states decreased with an increase in the number of dry-wet cycles.

This significant change in the elastic modulus for different numbers of dry-wet cycles indicated that the deformation resistance of HWMs with different water-to-cement ratios varies considerably under the dry-wet cycle. HWMs with smaller water-to-cement ratios have lower porosity and stronger strength recovery ability. Thus, the degradation rate of elastic modulus increased with an increase in the waterto-cement ratio.

3.3. Macroscopic Damage Analysis. Figure 7 shows the saturated specimens under different dry-wet cycles with a water-to-cement ratio of $4: 1$. It was found that the surface of an HWM would be damaged with an increase in the number of dry-wet cycles. Taking the saturated specimens with a water-to-cement ratio of $4: 1$ as an example, when the number of dry-wet cycles was 6 , damage was observed the

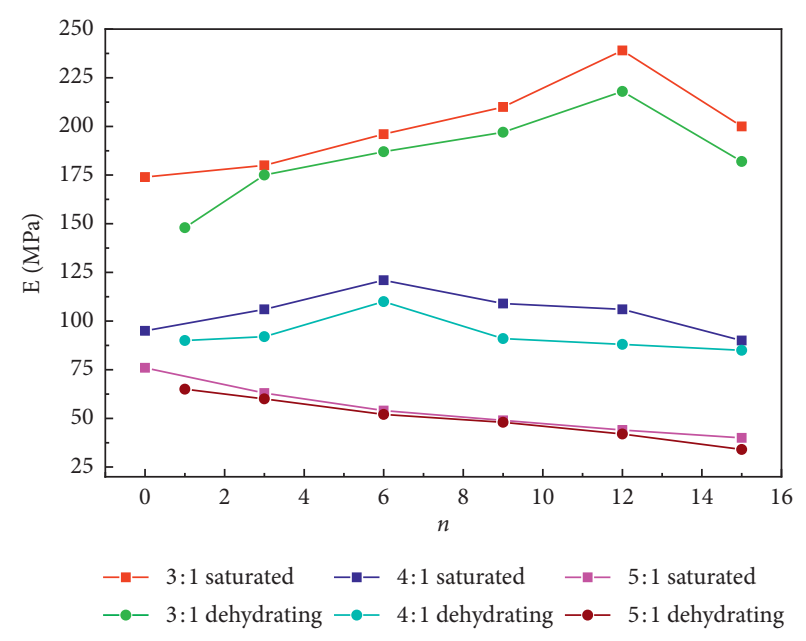

FIGURE 6: Relationship between elastic modulus and dry-wet cycles.

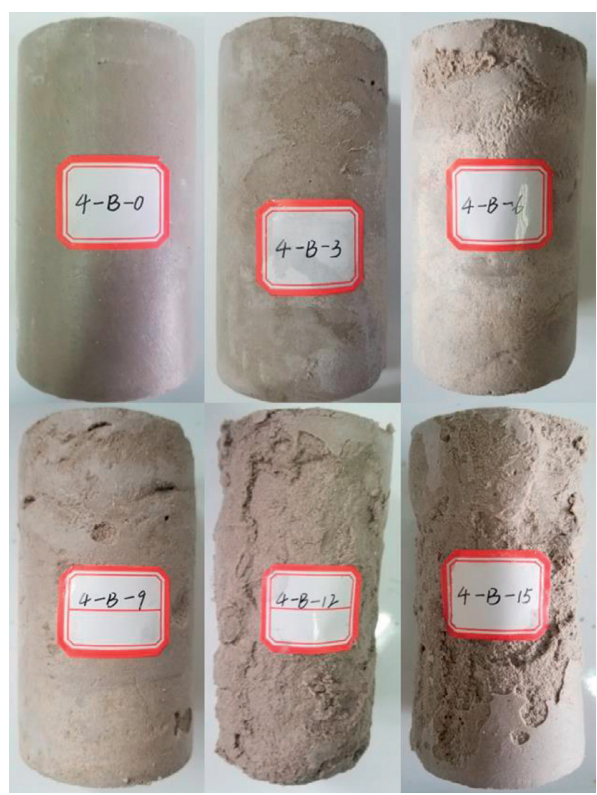

FIGURE 7: Saturated specimens under different dry-wet cycles.

surface of the specimens, where the peak stress was the maximum. The specimens in the dehydrated state were the same as those in saturated. When the water-to-cement ratio was $3: 1$, damage was observed on the surface of the specimens when the number of dry-wet cycles was 12 . However, when the water-to-cement ratio was $5: 1$, damage was observed on the specimen at the beginning of the dry-wet cycle. It can be seen that the degree of surface damage on the specimens corresponds to a decrease in peak stress.

Corrosion failure of the specimen was the result of the combined action of carbonation and water erosion. The carbonized product was powder, which would fall off in water. As shown in Figure 7, the corrosion damage first appeared on the surface and gradually developed inside the samples. With the increase of the dry-wet cycle time, the corrosion effect was more obvious, and the corrosion products fall off more widely. 
Figure 8 shows the saturated specimens at three waterto-cement ratios for the same number of dry-wet cycles. It can be found that the higher the water-to-cement ratio, the more obvious the damage caused by the dry-wet cycle. The water-cement ratio of the sample is directly proportional to the porosity and free-water content. Therefore, carbonation and corrosion failure of samples are more likely to occur with a high water-cement ratio. HWMs with low watercement ratio have better resistance against dry-wet cycles. In engineering, the appropriate water-cement ratio can be selected according to the severity of the environment.

The experiments indicated that HWMs had different failure modes for different numbers of dry-wet cycles. Figure 9 shows the failure morphology diagram of the saturated specimens with different numbers of dry-wet cycles with a water-to-cement ratio of $4: 1$. Failure modes can be divided into the following two categories based on whether the specimen was corrosion damaged or not. When the specimens were not damaged, the failure mode of the specimens was splitting failure; otherwise, it was shearsplitting failure. The failure mode of the specimens in the dehydrated state was the same as those in the saturated state. Similarly, when the number of dry-wet cycles was less than 12 , the failure mode of the specimens with a water-to-cement ratio of $3: 1$ was splitting failure; otherwise, the failure mode was shear-splitting failure. However, all the specimens with a water-to-cement ratio of 5:1 exhibited shear-splitting failure.

HWM exhibits good homogeneity. The crack at the end of the specimen can form a through crack, which is called splitting failure. The corrosion damage caused by the drywet cycles changed the homogeneity of the samples. A weak plane structure would be formed in the area with serious corrosion damage. When the specimens were damaged under compression, an inclined crack would appear in the weak plane structure. The failure mode with inclined crack and through crack is called shear-splitting failure.

\section{Microscopic Analysis}

4.1. Analysis of Dry-Wet Cycle Mechanism. The main component of HWMs is ettringite crystal, whose chemical formula is expressed as $3 \mathrm{CaO} \cdot \mathrm{Al}_{2} \mathrm{O}_{3} \cdot 3 \mathrm{CaSO}_{4} \cdot 32 \mathrm{H}_{2} \mathrm{O}$. The study found that the amount of ettringite in HWM would decrease with an increase in the water-to-cement ratio, and the internal structure would become loose [13]. In this study, an HWM with a water-to-cement ratio of $4: 1$ was selected for microscopic analysis.

The HWM not only lost some of their free water but also reacted with carbon dioxide in a dehydration process called carbonization. The degree of carbonization gradually decreased from the surface toward the center of the specimen. Therefore, the specimen would have the structure weathering layer-transition layer-unweathered layer after the drywet cycle.

It can be seen from Table 3 that the strength of the specimens decreased after a dehydration process. Two reasons can be attributed to this phenomenon. First, the specimens would lose some free water, resulting in increased

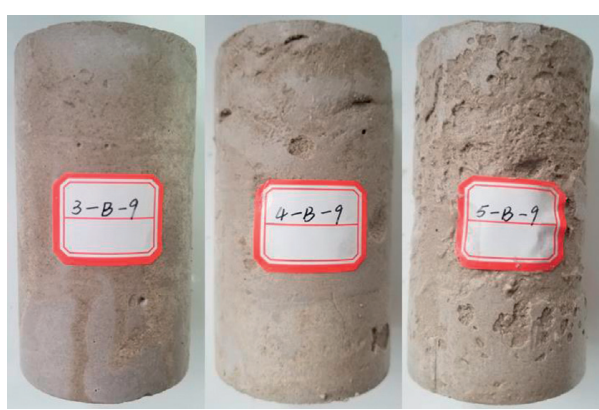

FIgURE 8: Saturated specimens with different water-to-cement ratios under the same number of dry-wet cycles.

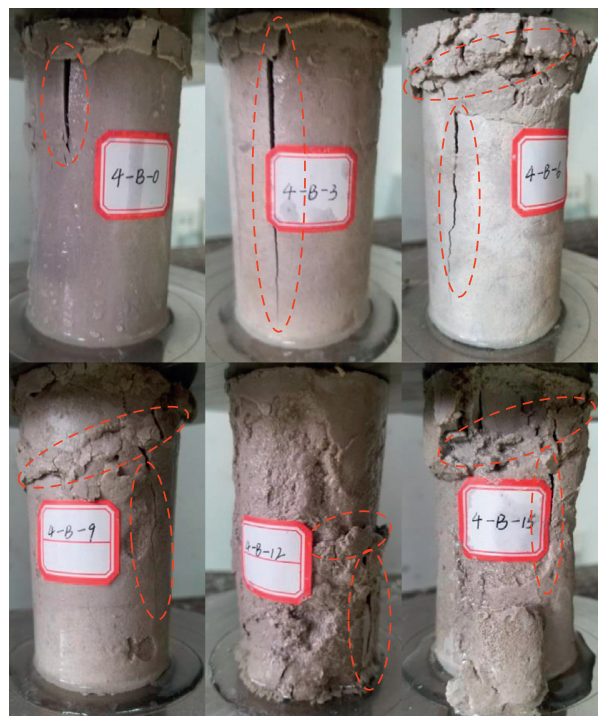

FIGURE 9: Failure morphology diagram of saturated specimens under different dry-wet cycles with a water-to-cement ratio of $4: 1$.

porosity of the specimens. On the other hand, a part of ettringite, which contributes toward strength, reacted with carbon dioxide [23]. Based on the amount of humidity present in air, there are two main carbonization processes.

When the humidity is higher, the carbonization process is represented by the following equation:

$$
\begin{aligned}
3 \mathrm{CaO} & \cdot \mathrm{Al}_{2} \mathrm{O}_{3} \cdot \mathrm{CaSO}_{4} \cdot 32 \mathrm{H}_{2} \mathrm{O}+3 \mathrm{CO}_{2}+\mathrm{H}_{2} \mathrm{O} \\
& \longrightarrow \mathrm{CaSO}_{4} \cdot 2 \mathrm{H}_{2} \mathrm{O}+3 \mathrm{CaCO}_{3}+\mathrm{Al}_{2} \mathrm{O}_{3} \cdot \mathrm{H}_{2} \mathrm{O}+30 \mathrm{H}_{2} \mathrm{O}
\end{aligned}
$$

When humidity is lower, carbon dioxide reacted directly with ettringite, as represented by the following equation:

$$
\begin{aligned}
& 3 \mathrm{CaO} \cdot \mathrm{Al}_{2} \mathrm{O}_{3} \cdot \mathrm{CaSO}_{4} \cdot 32 \mathrm{H}_{2} \mathrm{O}+3 \mathrm{CO}_{2} \\
& \longrightarrow \mathrm{CaSO}_{4} \cdot 2 \mathrm{H}_{2} \mathrm{O}+3 \mathrm{CaCO}_{3}+2 \mathrm{Al}(\mathrm{OH})_{3}+27 \mathrm{H}_{2} \mathrm{O}
\end{aligned}
$$

It can also be seen from Table 3 that the strength of the saturated specimens was higher than that of dehydrated specimens for the same number of dry-wet cycles. The main reason for strength recovery after water absorption was that the increase in porosity provided sufficient space for 


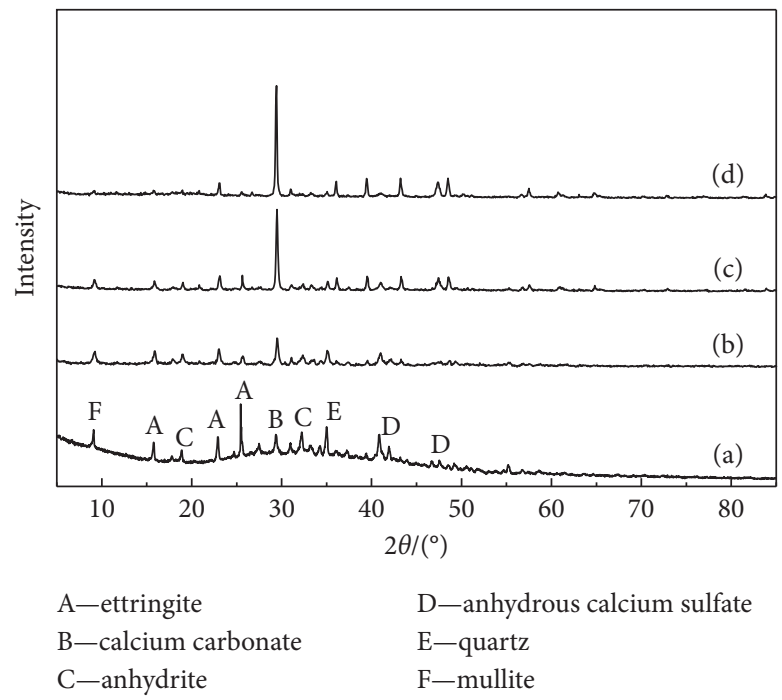

FIGURE 10: XRD phase analysis of HWM in different states: (a) 4-B-0; (b) the internal of 4-B-12; (c) the surface of 4-B-12; (d) the surface of 4-S-12.
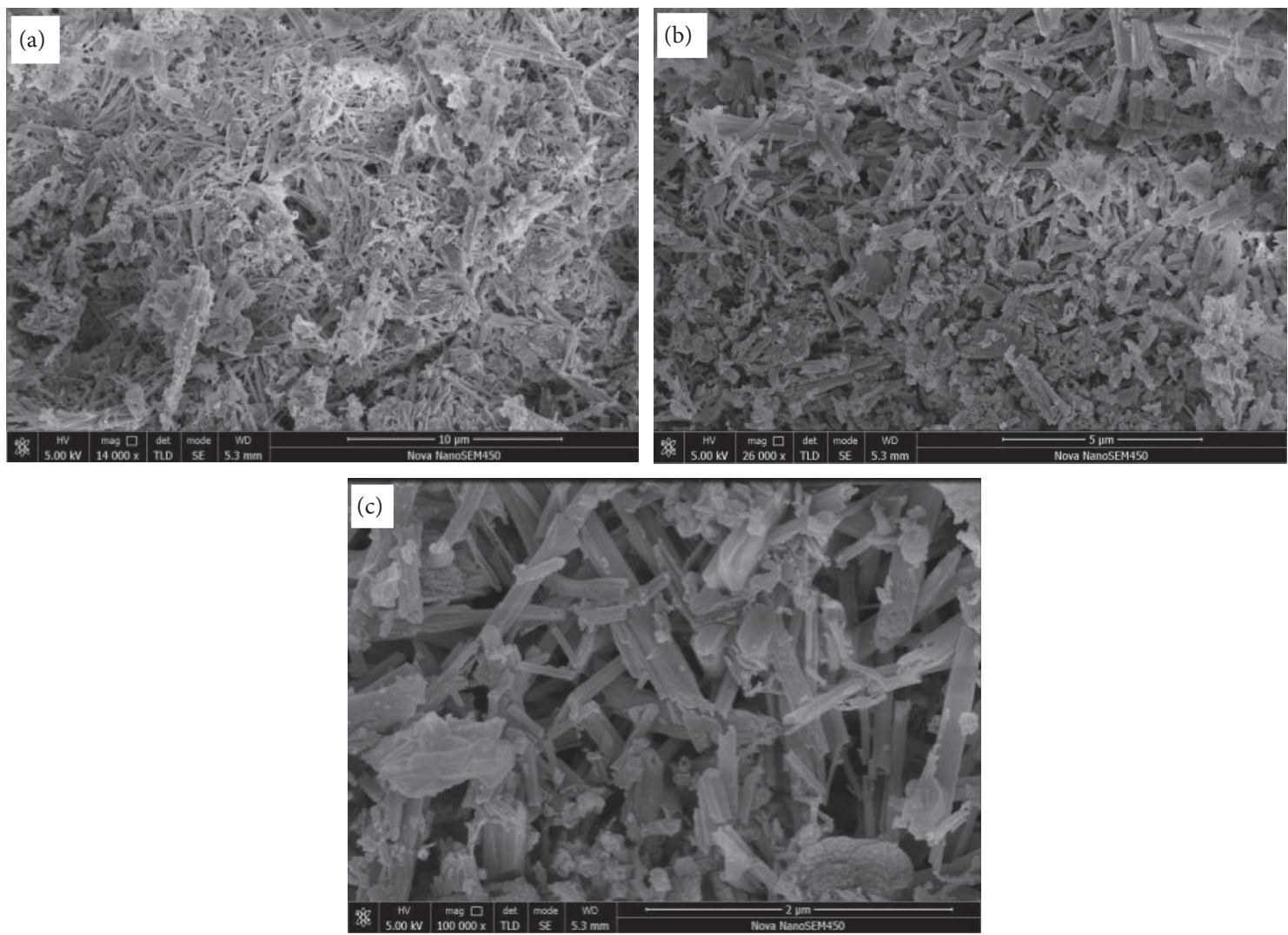

Figure 11: SEM images of the internal of 4-B-12: (a) 14000 times, (b) 26000 times, and (c) 100000 times.

ettringite formation. Ettringite is regenerated through two processes: the remaining raw materials in the specimens continue to react to form ettringite, and calcium carbonate and other substances are converted into ettringite. The continuous reaction of the remaining raw materials is the main factor for strength regeneration of HWMs. As the water-to-cement ratio decreases, the amount of raw materials increases. Thus, strength recovery is more obvious. The 

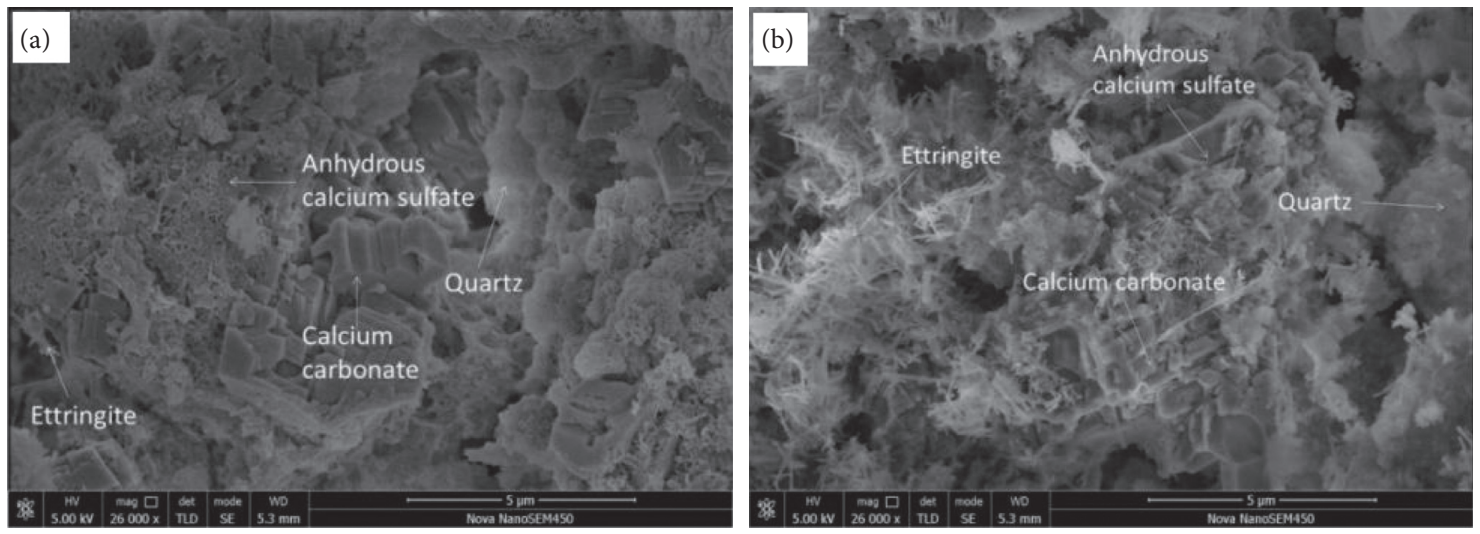

Figure 12: SEM images of the surface of (a) 4-S-12 (26000 times) and (b) 4-B-12 (26000 times).

strength regeneration process is consistent with the hydration hardening mechanism of HWM, as represented by the following equations [24]:

$$
\begin{aligned}
& 3 \mathrm{CaO} \cdot 3 \mathrm{Al}_{2} \mathrm{O}_{3} \cdot \mathrm{CaSO}_{4}+2\left(\mathrm{CaSO}_{4} \cdot 2 \mathrm{H}_{2} \mathrm{O}\right)+34 \mathrm{H}_{2} \mathrm{O} \\
& \quad \longrightarrow 3 \mathrm{CaO} \cdot \mathrm{Al}_{2} \mathrm{O}_{3} \cdot 3 \mathrm{CaSO}_{4} \cdot 32 \mathrm{H}_{2} \mathrm{O}+2\left(\mathrm{Al}_{2} \mathrm{O}_{3} \cdot 3 \mathrm{H}_{2} \mathrm{O}\right)(\mathrm{gel})
\end{aligned}
$$

$$
\begin{gathered}
\mathrm{Al}_{2} \mathrm{O}_{3} \cdot 3 \mathrm{H}_{2} \mathrm{O}(\mathrm{gel})+3 \mathrm{Ca}(\mathrm{OH})_{2}+3\left(\mathrm{CaSO}_{4} \cdot 2 \mathrm{H}_{2} \mathrm{O}\right) \\
+20 \mathrm{H}_{2} \mathrm{O} \longrightarrow 3 \mathrm{CaO} \cdot \mathrm{Al}_{2} \mathrm{O}_{3} \cdot 3 \mathrm{CaSO}_{4} \cdot 32 \mathrm{H}_{2} \mathrm{O}
\end{gathered}
$$

To verify the above mechanism, XRD phase analysis was performed on materials with a water-to-cement ratio of $4: 1$ in different states. Figure 10 shows that, with an increase in the number of dry-wet cycles, the degree of carbonization on the specimens' surface is greater than that on the specimens' center. It can also be seen that the calcium carbonate content decreased and ettringite content increased after a water absorption process. The results shown in Figure 10 are consistent with those of the above analysis of the dry-wet cycle mechanism.

4.2. Microstructure of HWM. Ettringite crystal is a network structure, which not only contains a large amount of bound water but can also absorb a large amount of free water. With an increase in the water-to-cement ratio, the amount of ettringite crystal in HWM decreases, and the structure becomes more loose, which will increase moisture content and decrease strength $[25,26]$.

Figure 11 shows the microscopic morphology of the unweathered layer at different magnifications after 12 drywet cycles, which is consistent with the results shown in Figure 9. The unweathered layer contains various substances, mainly ettringite with a columnar structure. Figure 12 shows the micromorphology of the surface of specimens in the dehydrated state and saturated state after 12 dry-wet cycles. Figure 12(a) shows almost entirely lumpy calcium carbonate with coarse pores that almost lose their carrying capacity. Some amount of ettringite is formed, and the pores are significantly reduced and shrunk, thus enhancing strength in Figure 12(b).

\section{Conclusions}

By experimenting with ETM machine, SEM, and XRD technology, the mechanical properties and microchange mechanism of HWM at different water-cement ratios were thoroughly investigated under the specified dry-wet cycles. The effect of the dry-wet cycles on HMW's peak stress, elastic modulus, and failure mode was obvious.

For HWM with water-cement ratios of $3: 1$ and $4: 1$, the peak stress and elastic modulus both first increased with an increasing number of dry-wet cycles before starting to decrease after 12 and 6 dry-wet cycles, respectively. However, the HWM with a water-to-cement ratio of $5: 1$ displayed a different tendency from the former two scenarios, which is that the two parameters, peak stress and elastic modulus, never exhibited tendency change but decreased all the way with increasing dry-wet cycles. Hence, the maximum of peak stress and elastic modulus was observed when there was no dry-wet cycle. For all the specimens, as the peak stress decreased from the maximum value, the failure mode also changed from splitting failure to shear-splitting failure.

From a microscopic point of view, carbonization reaction during dehydration and strength regeneration during saturation were the main factors leading to a change in the strength of the specimens. With an increasing number of water-cement ratios, the porosity and the remaining raw materials of the specimens increased and decreased, respectively. Therefore, different water-cement ratios have different dry-wet cycle effects, namely, the degradation rate of peak stress and elastic modulus increased with an increasing number of water-to-cement ratios.

Finally, based on the above test results, an appropriate water-cement ratio can be selected according to the specific construction environment.

\section{Data Availability}

The data used to support the findings of this study are included within the article. As for the raw data of the article, we make the following explanation: (1) high-water materials mechanics data were obtained by uniaxial compression tests using MTS microcomputer-controlled electrohydraulic servo universal testing machine in Sichuan University. (2) 
The microstructure and composition of the materials were analyzed by means of SEM and XRD equipment in the analysis and testing center of Sichuan University. We can ensure that all the data are true and reliable in the article. All the raw data can be provided in the format of Word, Excel, or PDF at any time.

\section{Conflicts of Interest}

The authors declare no conflicts of interest.

\section{Acknowledgments}

This research was funded by the National Natural Science Foundation of China (grant no. 51604006).

\section{References}

[1] G. Strozik, "The use of fly ash for filling the shallow underground ore mine works on the example of the mine reclamation area in Piekary Slaskie," Gospodarka Surowcami Mineralnymi-Mineral Resources Management, vol. 34, no. 1, pp. 139-153, 2018.

[2] L. Bertolini, M. Carsana, and M. Spada, "Filling of a flooded gypsum mine with a flowable soil-cement mix," Journal of Materials in Civil Engineering, vol. 22, no. 6, pp. 628-636, 2010.

[3] A. K. Gupta and B. Paul, "A review on utilisation of coal mine overburden dump waste as underground mine filling material: a sustainable approach of mining," International Journal of Mining and Mineral Engineering, vol. 6, no. 2, pp. 172-186, 2015.

[4] O. Gibert, J. de Pablo, J. Luis Cortina, and C. Ayora, "Evaluation of municipal compost/limestone/iron mixtures as filling material for permeable reactive barriers forin-situ acid mine drainage treatment," Journal of Chemical Technology \& Biotechnology, vol. 78, no. 5, pp. 489-496, 2003.

[5] Y. G. Zhang and F. B. Dong, "Research and practice of new mining technologies by backfilling with refuse under buildings in town," Coal Mining Technology, vol. 13, no. 1, p. 31, 2008.

[6] A. L. Wang, L. Q. Ma, Z. W. Wang et al., "Soil and water conservation in mining area based on ground surface subsidence control: development of a high-water swelling material and its application in backfilling mining," Environment Earth Science, vol. 75, no. 9, 2016.

[7] Z. P. Yan, T. Y. Qi, L. X. Zhang et al., "Study of ZKD quicksetting materials with high water content and technique of pump packing," China Coal Society, vol. 22, no. 3, p. 270, 1997.

[8] R. Evans, "High density paste fill for the mine under the rain forest - solution for difficult ground in extremely sensitive environment," Canadian Mining Journal, vol. 119, no. 6, p. 13, 1998.

[9] T. Q. Chen and X. F. Dang, "Experiment of backfill mining with Aeolian sand high water swelling materials in Yuyang Caol Mine," Industry and Mine Automation, vol. 43, no. 6, pp. 72-76, 2017.

[10] B. B. Guo, C. W. Liu, D. F. Liu et al., "Experimental study on mechanical properties of high water quick-setting materials in marine environment," Fresenius Environment Bulletin, vol. 27, no. 2, pp. 1269-1281, 2018.
[11] X. P. Xie, C. M. Hu, and M. F. Liang, "Application of grouting reinforcement of high water materials in panel substation," Coal Mining, vol. 23, no. 3, pp. 56-58, 2018.

[12] C. Y. Song, X. L. Cheng, and Z. L. Wang, "Weathering mechanism of ettringite," University of Science and Technology Beijing, vol. 21, no. 5, p. 459, 1999.

[13] X. L. Li and C. W. Liu, "Mechanical properties and damage constitutive model of high water materials at different loading rates," Advanced Engineering Materials, vol. 20, no. 6, 2018.

[14] Z. Qin, X. X. Chen, and H. L. Fu, "Damage features of altered rock subjected to drying-wetting cycles," Advances in Civil Engineering, Article ID 5170832, 10 pages, 2018.

[15] Q. Y. Ma, P. Y. Yu, and P. Yuan, "Experimental study on creep properties of deep siltstone under cyclic wetting and drying," Chinese Journal of Rock Mechanics and Engineering, vol. 37, no. 3, p. 593, 2018.

[16] H. J. Li, Y. C. Zhang, L. Xu et al., "Examination of the treatment quality of filling mine-out voids using super-highwater material by the TEM technique," Environment Earth Science, vol. 76, no. 3, 2017.

[17] Y. Shim, G. Hong, and S. Choi, "Autogenous healing of earlyage cementitious materials incorporating superabsorbent polymers exposed to wet/dry cycles," Materials, vol. 11, no. 12, 2018.

[18] X. J. Yang, J. M. Wang, and D. G. Hou, "Effect of dry-wet cycling on the mechanical properties of rocks: a laboratoryscale experimental study," Processes, vol. 6, no. 10, 2018.

[19] X. X. Chen, P. He, and Z. Qin, "Damage to the microstructure and strength of altered granite under wet-dry cycles," Symmetry Basel, vol. 10, no. 12, 2018.

[20] X. G. Wang, H. B. Zhan, J. D. Wang et al., "The stability of tailings dams under dry-wet cycles: a case study in Luonan, China," Water, vol. 10, no. 8, p. 1048, 2018.

[21] J.-p. Zuo, Z.-j. Hong, Z.-q. Xiong, C. Wang, and H.-q. Song, "Influence of different W/C on the performances and hydration progress of dual liquid high water backfilling material," Construction and Building Materials, vol. 190, pp. 910-917, 2018.

[22] Q. Chang, W. Tang, Y. Xu, and H. Zhou, "Research on the width of filling body in gob-side entry retaining with highwater materials," International Journal of Mining Science and Technology, vol. 28, no. 3, pp. 519-524, 2018.

[23] T. Grounds, H. G Midgley, and D. V Novell, "Carbonation of ettringite by atmospheric carbon dioxide," Thermochimica Acta, vol. 135, pp. 347-352, 1988.

[24] H.-J. Kuzel, "Initial hydration reactions and mechanisms of delayed ettringite formation in Portland cements," Cement and Concrete Composites, vol. 18, no. 3, pp. 195-203, 1996.

[25] Y. Fu, S. A. Sheikh, and R. D. Hooton, "Microstructure of highly expansive cement pastes," ACI Materials Journal, vol. 91, no. 1, pp. 46-53, 1994.

[26] J. C. Guo, "The hydrates and microstructure of permeablity resisting portland cement," Wuhan University of TechnologyMaterials Science Edition, vol. 15, no. 1, pp. 34-37, 2000. 